\title{
O DIREITO INTERNACIONAL E AS ABORDAGENS DO “TERCEIRO MUNDO”: CONTRIBUIÇÕES DA TEORIA CRÍTICA DO DIREITO
}

\author{
INTERNATIONAL LAW AND “THIRD WORLD” APPROACHES: \\ CONTRIBUTIONS OF THE CRITICAL LEGAL THEORY
}

\author{
Arno Dal Ri Júnior \\ Universidade Federal de Santa Catarina - UFSC (Florianópolis, SC, Brasil) \\ Chiara Antonia Sofia Mafrica Biazi \\ Universidade Federal de Santa Catarina - UFSC (Florianópolis, SC, Brasil) \\ Taciano Scheidt Zimmermann \\ Universidade Federal de Santa Catarina - UFSC (Florianópolis, SC, Brasil)
}

Recebimento: 16 jun. 2016

Aceitação: 24 jan. 2017

\begin{abstract}
Como citar este artigo / How to cite this article (informe a data atual de acesso / inform the current date of access):
DAL RI JÚNIOR, Arno; BIAZI, Chiara Antonia Sofia Mafrica; ZIMMERMANN, Taciano Scheidt. O direito internacional e as abordagens do "Terceiro Mundo": contribuições da teoria crítica do direito. Revista da Faculdade de Direito UFPR, Curitiba, PR, Brasil, v. 62, n. 1, jan./abr. 2017, p. 61 - 81. ISSN 2236-7284. Disponível em: <http://revistas.ufpr.br/direito/article/view/47216>. Acesso $\quad$ em: $30 \quad$ abr. $2017 . \quad$ DOI: http://dx.doi.org/10.5380/rfdufpr.v62i1.47216.
\end{abstract}

\section{RESUMO}

O presente artigo tenciona estimular uma reflexão crítica sobre conceitos centrais do direito internacional, ao jogar luz sobre certas continuidades históricas colonializantes que permanecem subjacentes na construção da disciplina. Valendo-se da teoria crítica, propõe um questionamento de premissas não declaradas que sustentam o sistema jurídico internacional, aqui compreendido a partir do ponto de vista do movimento político do "Terceiro Mundo". A teoria crítica geralmente percebe o direito internacional como expressão das contradições da política internacional e, em seu prognóstico, funda-se na subversão material de um sistema: um movimento que se inicie a partir das contradições da realidade política. Essa pesquisa delineia algumas das contribuições desse sistema de pensamento para a construção do direito internacional, especialmente no que diz respeito à inclusão de sujeitos historicamente excluídos na participação nos processos decisórios internacionais, com vistas ao desenvolvimento de um outro framework de relações e interações entre todos os sujeitos que fazem parte da comunidade internacional.

\section{PALAVRAS-CHAVE}

Direito internacional. Teoria crítica do direito. Reforma da ordem jurídica internacional. Neocolonialismo. Política internacional.

\begin{abstract}
The purpose of this article is to stimulate a critical reflection on central concepts of international law by throwing some light on colonizing historical continuities that remain subjacent to its construction. Relying on critical theory, it proposes a questioning of non-declared premises that sustain the
\end{abstract}


international legal system, which is here understood through the point of view of the political movement of the "Third World". The critical theory generally sees international law as an expression of the contradictions of international politics and, in its prognostics, founds itself on a material subversion of the system: a movement that comes from the very contradictions of the political reality. This research delineates some of the contributions of this system of thought to the construction of international law, especially with regard to the inclusion of historically excluded subjects as participants in international decision processes, with a view to produce in the international community a new framework of relations and interactions among all the subjects that are part of it.

\section{KEYWORDS}

International law. Critical legal theory. Reform of the international legal order. Neocolonialism. International politics.

\section{INTRODUÇÃO}

O direito internacional - no sentido mais específico de um international law - emergiu, principalmente a partir da segunda metade do século XIX, como um sistema jurídico essencialmente europeu imbuído, politicamente, de uma certa missão civilizadora. As normas jurídicas e os instrumentos teóricos derivados desse sistema serviram de ferramentas úteis a propósitos históricos, colonializantes, e carregavam em si a contradição fundamental que opunha povos civilizados e não civilizados. Seria somente após a criação da Organização das Nações Unidas, em 1945, e a subsequente consolidação dos movimentos de descolonização nas décadas que se seguiram, que seria possível enxergar, após a ruptura política do paradigma europeu, uma resposta do emergente Terceiro Mundo ao afã civilizador do direito internacional.

Muito embora o colonialismo enquanto categoria normativa tenha desaparecido formalmente do direito internacional, não se pode negar que continuidades históricas não declaradas - traços da colonialidade - permanecem como herança das feridas abertas nos territórios e nas populações colonizadas nos séculos passados. Nesse contexto, é indispensável uma reflexão crítica das categorias de pensamento que fundamentam o direito internacional, a fim de que se consiga identificar possíveis premissas escondidas, remanescentes, que informam as relações entre os países nos dias de hoje. O aporte da teoria crítica no âmbito jurídico internacional, nesse ponto, é crucial.

Contra esse pano de fundo, o objetivo deste artigo é revisitar algumas das contribuições da teoria crítica do direito ao direito internacional, especialmente a partir da perspectiva do Terceiro Mundo, a fim de extrair delas elementos para interpretar as modificações concretas e a atual configuração do sistema. Para isso, começaremos tratando de conceitos fundamentais do direito internacional europeu, no século XIX, especialmente, analisando-os anatomicamente. Depois, abordaremos o fenômeno político do surgimento do bloco dos países de Terceiro Mundo como uma 
alternativa pragmática, fundada nas contradições políticas da realidade, às visões dominantes na comunidade internacional do século XX. Por fim, traremos à baila alguns autores expoentes da teoria crítica do direito e dos estudos pós-coloniais, com o intento de ali explorar as respostas teóricas que, a partir daquela primeira subversão, se engendraram, com vistas à integração política e, finalmente, jurídica, dos sujeitos deixados à margem dos processos internacionais de decisão nos séculos anteriores.

\section{O DIREITO INTERNACIONAL EUROPEU DO SÉCULO XIX: NAÇÃO E CIVILIZAÇÃO}

A partir dos ensinamentos de Mancini ${ }^{1}$, um dos artífices do Risorgimento, iniciou-se um novo momento na ciência internacionalista ${ }^{2}$. Em oposição à ordem derivada da Paz de Vestfália ${ }^{3}$, sob cujos ditames o direito internacional tinha como principais sujeitos os Estados, a concepção de Mancini era a de que o sujeito central do ordenamento jurídico internacional não deveria ser o Estado, mas a Nação ${ }^{4}$.

Em síntese, o autor italiano defendeu que a família e a Nação eram as duas formas perpétuas da associação humana, “companheiras inseparáveis do homem social” (MANCINI, 2003, p. 35). Enquanto o Estado nascia do arbítrio humano, a Nação, “ideia-mãe da ciência”, emanava do seio de um povo, a partir de elementos materiais comuns à população e, também, de um elemento espiritual: uma “consciência da nacionalidade”. Para Mancini, a luta entre Estado e Nação traduzia-se numa luta dos “artifícios humanos contra as necessidades da natureza” (MANCINI, 2003, p. 70) sendo os primeiros dotados de uma perene impotência em relação às segundas. Assim, como princípio basilar

\footnotetext{
1 Jurista, advogado e parlamentar italiano do século XIX. Principal responsável pela criação e consolidação do "princípio da nacionalidade”. Sua principal contribuição ao direito internacional, a preleção de 1851, encontra-se publicada, entre outros, em MANCINI, Pasquale Stanislao. Della nazionalità come fondamento del diritto delle genti. Torino: tipografia Eredi Botta, 1851; a obra foi publicada no Brasil no âmbito de MANCINI, Pasquale Stanislao. Direito internacional (Diritto Internazionale. Prelezioni). Ijuí: Unijuí, 2003; DAL RI JR., Arno. A Nação contra o Estado. A Ciência do Direito Internacional no "Risorgimento" italiano. Anuário Brasileiro de Direito Internacional, 1 (2012), p. 69 et seq.; DAL RI JR., Arno. Pasquale Stanislao Mancini. In: DAL RI Jr., Arno; VELOSO, Paulo Potiara de Alcântara; LIMA, Lucas Carlos (Org.). A Formação da Ciência do Direito Internacional. Ijuí: Unijuí, 2014, p. 253283 et cetera.

2 "Sobre o que girava a política internacional entre os anos de 1848 e 1870? A historiografia tradicional ocidental tem pouca dúvida a este respeito: era sobre a criação de uma Europa de nações-estados.” (HOBSBAWM, 2009, p. 101)

${ }^{3}$ Pôs fim à Guerra dos Trinta Anos que assolou a Europa ao longo da primeira metade do século XVII, sendo que a partir desse momento inaugurou-se o moderno sistema internacional.

4 Fazem parte do conceito manciniano de Nação elementos de duas espécies: material e espiritual. Na primeira classificação, encaixam-se aqueles elementos palpáveis relacionados à vida de um povo, tais como a região em que habita, a religião que professa, a língua que fala, os costumes que possui, a lei que o rege e sua história comum. Na segunda espécie, tem-se a consciência da nacionalidade, que, nas palavras de Mancini, seria "o sentimento que ela [a Nação] adquire de si mesma e que a torna capaz de se constituir internamente e de se manifestar externamente." (MANCINI, 2003, p. 39)
} 
do direito na divisão dos povos, a nacionalidade ofereceria critérios "bem mais certos e duradouros que os instáveis arbítrios das combinações diplomáticas” referentes às abstrações estatais.

A pretendida substituição do principal sujeito do direito internacional - do Estado para a Nação - conduziu o pensamento jurídico internacional por caminhos até então inexplorados ${ }^{5}$. E tão revolucionários se diziam os ensinamentos que, nos discursos de Mancini, falava-se de um "Novo Direito das Gentes", em oposição ao "Velho Direito das Gentes”6. Não obstante, foi em meio a rupturas e continuidades que a difusão dessa concepção afetou profundamente os rumos do direito internacional no apagar das luzes do século XIX ${ }^{7}$.

Uma das mais importantes influências desse pensamento sobre o direito internacional - e aí talvez uma continuidade subjacente à pretendida mudança - revelou-se no fato de que este, mesmo quando começou a ser pensado a partir do princípio da nacionalidade, reafirmou sua identidade de um direito exclusivamente voltado aos povos então considerados “civilizados”8. Naquele contexto, praticamente não se pensava em aplicar os princípios e as normas jurídicas internacionais aos povos e países “não-civilizados”9 (BIAZI, 2014, p. 109). Pelo menos não do mesmo modo.

\footnotetext{
5 De certo modo, Friedrich Carl von Savigny apresenta com a publicação do Vom Beruf, em 1814, uma síntese do conceito de Nação pautada em ideias que já circulavam no Ius Publicum Europaeum que marcou o século XVIII. Mas, diferentemente dos fins a que se propunha Mancini, a elaboração de Savigny era sobretudo funcional à doutrina que se opôs à codificação do direito privado, tornando-a funcional a uma estratégia de resistência ao estatalismo iluminista e contratualista que arrebanhava sempre mais adeptos na cultura jurídica alemã no início do século XIX. Da maneira como foi construído, o conceito parte do pressuposto de que o fenômeno jurídico possui seu conteúdo moldado pela “consciência moral”, pelo espírito e pelos costumes do povo que o origina. O conceito pode ser observado em alguns trechos do Vom Beruf, sendo delineado neste como coletividade política que ao ser construída absorve elementos históricos e culturais que a identificam e a diferenciam em relação às demais. Savigny utiliza tal ideia quando se contrapõe à fúria dos codificadores, ao levantar a voz em favor do respeito ao que seria o "espírito da Nação”. Este último, segundo o professor de Berlin, se encontraria em diversos aspectos da vida cultural, refletindo-se no percurso histórico das instituições do direito civil (SAVIGNY, 1814, p. 65). Vide, também, SAVIGNY, Friedrich Carl. System des heutigen römischen Rechts. Erster Band. Berlin: Veit und Comp., 1849, p. 33 et seq. Ainda, a respeito, DAL RI JR., Arno. O Direito como historicismo jurídico humanista: Friedrich Carl von Savigny. In: WOLKMER, Antonio Carlos (Org.). Fundamentos do Humanismo Jurídico no Ocidente. São Paulo: Manole, 2005.

6 1852, preleção proferida na Real Universidade de Turim.

7 Alguns autores que, ainda no século XIX, dedicaram-se a - direta ou indiretamente - analisar o princípio lançado por Mancini: DELOCHE, Maximin. Du Principe des Nationalités. Paris: Guillaumin, 1860, p. 31 et seq.; JOZON, Paul. Exposition à la séance du 17 février 1870 de la Société de législation comparée. Bulletin de la Société de législation comparée, 2 (1870), p. 73 et seq.; HOLTZENDORFF, Franz von. Le principe des nationalités et la littérature italienne du droit des gens. Revue de Droit International et Législation Comparée, 2, 1870, p. 96 et seq.; PADELLETTI, Guido. L’Alsace et la Lorraine, et le droit des gens. Revue de droit international et de législation comparée, III (1871), p. 494 et seq.; FIORE, Pasquale. Nuovo diritto internazionale pubblico secondo i bisogni della civilità moderna. Milano: Autori-editori, 1865, p. 45 et seq.; BLUNTSCHLI, Johann Caspar. Das moderne Völkerrecht der civilisirten Staaten als Rechtsbuch. Nördlingen: Beck, 1878, p. 70 et seq.; FIORE, Pasquale. Trattato di diritto internazionale pubblico secondo i bisogni della civilità moderna. Milano: Autori-editori, 1879, p. 207 et seq. et cetera.

${ }^{8}$ Esse fenômeno é exposto com peculiar clareza na obra de KOSKENNIEMI, Marti. The Gentle Civilizer of Nations. The Rise and Fall of International Law 1870-1960. Cambridge: Cambridge University Press, 2001.

${ }^{9}$ Para um pensamento da época, conferir OPPENHEIM, Lassa. International Law: A treatise. London: Longman Greens and Co., 1905, v. 1, p. 148-149.
} 
Para Louis Le Fur (1931, p. 9) não é que não haveria nenhum direito das gentes a ser aplicado às populações não civilizadas, bárbaras, selvagens, mas sim que o direito a ser aplicado a elas não seria o mesmo que regia os “Estados civilizados”. Na época, Paul Fauchille (1921, p. 160) também se referiu a um fosso profundo que separava os Estados europeus dos americanos, e de suas colônias, o que impossibilitaria a aplicação de um mesmo direito internacional em termos universais. Foi assim que o direito internacional do período se tornou um produto exclusivo da cultura e da história europeias. O fio condutor da sua expansão foi o conceito de civilização. Para Koskenniemi (2001, p. 127), os juristas do século XIX queriam reafirmar o pedigree do direito internacional europeu e "utilizaram a distinção entre comunidades civilizadas e não-civilizadas para lidar com o processo de expansão europeia" ${ }^{10}$.

Considerável parcela desse pensamento deve-se ao fato de que, em Mancini, de mãos dadas com o conceito de nação como principal sujeito do direito internacional, veio à luz o fator “civilização"11, como "pressuposto indispensável” (COSTA, 2011) de validade e aplicabilidade do princípio da nacionalidade. Em suma, na obra de Mancini,

[...] [a] nação e o Estado emergem somente onde a história universal alcança o seu ápice, ou seja, nas sociedades do Ocidente. Somente para estas vale o nexo nação-Estado, que não pode ser estendido aos povos do Oriente e do Sul do mundo, ainda relegados à arcaica, prémoderna barbárie (COSTA, 2011, p. 4, grifo nosso).

Nesse contexto, os povos civilizados do ocidente europeu tomaram para si a nobre missão de civilizar o restante do mundo ${ }^{12}$. Tentariam cumpri-la também por meio do direito internacional. Como corolário desse afã civilizatório, o relacionamento entre os conceitos jurídicos internacionais e os povos não civilizados foi, na maioria das vezes, bastante conturbado. Desde as origens do variado

\footnotetext{
${ }^{10}$ Tradução nossa. Do original: "[...] and used the distinction between civilized and non-civilized communities to deal with the process of European expansion."

${ }^{11}$ Sobre o papel do conceito de "civilização" no direito internacional, vide BOWDEN, Brett. The Colonial Origins of International Law. European expansion and the classical standard of civilization. Journal of the History of International Law, n. 7, p. 1-23, 2005; ANGHIE, Antony. The Evolution of International Law: colonial and postcolonial realities. Third World Quarterly, vol. 27, n. 5, p. 739-753, 2006; ANGHIE, Antony. Francisco de Vitoria and the Colonial Origins of International Law. In: DARIAN-SMITH, Eve; ANGHIE, Antony (Org.). Imperialism, Sovereignty and Making of International Law. Cambridge: Cambridge University Press, 2004.

12 Sobre o tema, vide ANAYA, James. Indigenous Peoples in International Law. Nova Iorque: Oxford University Press, 1996, p. 24. E sobre o encontro entre civilização e barbárie no Brasil, Darcy Ribeiro conta que “[...] os índios perceberam a chegada do europeu como um acontecimento espantoso, só assimilável em sua visão mítica do mundo. [...] Pouco mais tarde, essa visão idílica se dissipa. [...] os índios começam a ver a hecatombe que caíra sobre eles. [...] Ao longo das praias brasileiras de 1500, se defrontaram, pasmos de se verem uns aos outros tal qual eram, a selvageria e a civilização. Suas concepções, não só diferentes mas opostas, do mundo, da vida, da morte, do amor, se chocaram cruamente.” (RIBEIRO, 1995, p. 42 et seq.)
} 
espectro de conceitos inerentes ao nacionalismo até a década de 1960, a barbárie, em especial as populações indígenas, ficou à margem da aplicação dos conceitos jurídicos chave daí derivados.

Ainda outra variável engrossa a história. Contra o pano de fundo da descolonização, pós 1945, consolidou-se na arena internacional o princípio jurídico da autodeterminação dos povos ${ }^{13}$. Desde suas raízes em Wilson e Lênin, a autodeterminação foi vista como coessencial à civilização ocidental e somente poderia vir a ser estendida a outras culturas em um longínquo futuro, uma vez que estas tivessem superado a distância que as separa do Ocidente graças à contribuição civilizadora da colonização (WRIGHT, 1988). Nas palavras de Pietro Costa, a convicção de que o direito internacional valia somente para os povos civilizados era "compartilhada pela cultura dominante entre os séculos XIX e XX, e [Wodroow] Wilson continua a se mover no seu alvéolo: daquela cultura ele extrai a visão da história e os pré-conceitos ocidentalistas” (COSTA, 2011, p. 4).

Enquanto, em algumas colônias, os povos civilizados iam-se tornando independentes pela autodeterminação, ainda estava por surgir a solução jurídica internacional a ser direcionada às populações não civilizadas - indígenas, especialmente -, as quais jamais poderiam autodeterminarse, pois não carregavam em si o pedigree civilizatório necessário a qualquer população que desejasse aceder à plenitude de um Estado-nação. Assim, confirmando-se o diagnóstico de Louis Le Fur, o direito internacional utilizado para lidar com os povos não civilizados seria diferente. Os princípios jurídicos foram, a partir daí, adaptados, forjados, preparados para cruzar, finalmente, a linha de inclusão-exclusão da civilização.

\section{O BLOCO DO TERCEIRO MUNDO ENQUANTO RESPOSTA POLÍTICA}

O direito internacional, nomeadamente até o começo do século XX, era, portanto, considerado como uma criação e prerrogativa nas nações ocidentais. Apenas as nações cristãs, europeias e civilizadas - à exceção de poucos estados, como a Turquia, por exemplo - podiam ser consideradas dignas de participarem da comunidade internacional. Por sua vez, as nações asiáticas, africanas e sul-americanas eram compreendidas como semicivilizadas ou bárbaras. Tudo isso, conforme Nuzzo, gerava um resultado prático excludente no que dizia respeito à participação política de tais sujeitos na vida da comunidade internacional:

\footnotetext{
13 Sobre o princípio da autodeterminação dos povos: SHAW, Malcolm Nathan. International law. Cambridge: Cambridge University Press. 6. ed., 2008, p. 251; LÊNIN, Vladimir. Obras Escogidas. Tomo 1. Moscú: Progreso, 1961; HART, Albert B. Selected Adresses and Public Papers of Woodrow Wilson. New York: Boni \& Liveright, Inc., 1918, p. 248; KINGSBURY, Benedict. Reconstructing Self-Determination: A Relational Approach. In: AIKIO, Pekka; SCHEININ, Martin. Operationalizing the Right of Indigenous Peoples to Self Determination. Turku: Åbo Akademi, 2000 .
} 
O déficit de cristandade e/ou de civilização tornava a consciência das populações não ocidentais incapaz de produzir direito, impedia a participação dessas à vida da comunidade internacional e as confiava aos princípios universais do direito natural que os Estados ocidentais teriam considerado aplicáveis em relação àquelas ${ }^{14}$ (NUZZO, 2012, p. 223, tradução nossa).

Em 1914, a maioria do mundo não europeu se encontrava controlado pelos maiores Estados europeus. Essa situação fazia com que os povos do mundo inteiro fossem assimilados, sem outra alternativa, a um sistema de direito que era essencialmente europeu, por derivar basicamente do pensamento e da experiência europeia (ANGHIE, 2004, p. 33). Nesse momento histórico, as doutrinas de viés positivista - que começaram a aparecer na última metade do século XIX - ocupavam um lugar relevante no pensamento jurídico, substituindo as teorias jusnaturalistas. Essa concepção teórica trazia consigo, como discurso histórico subjacente, a divisão fundamental entre povos civilizados e não civilizados, segundo as palavras de Anghie:

O direito internacional junaturalista que tinha sido usado nos séculos XVI e XVII afirmava que o direito internacional universal fosse aplicável a todos os povos, fossem esses cristãos ou não cristãos. Em contrapartida, o direito internacional positivista distinguia entre Estados civilizados e não civilizados e afirmava, ademais, que o direito internacional fosse aplicável apenas aos Estados soberanos que faziam parte da "família de nações” civilizada" (ANGHIE, 2004, p. 35, tradução nossa).

E, nesse contexto, foi por meio da colonização que os Estados europeus se apropriaram de territórios africanos, asiáticos e sul-americanos, isto é, do mundo inteiro, exercendo, aí, muito além das fronteiras da Europa, seus direitos de soberania. Nesse fato se vê que o direito internacional, ainda que em um movimento exógeno, levou consigo uma genética eminentemente europeia, ocidental e cristã, tendo-a como centro do mundo, pois esta era a realidade política sobre a qual ele operava. O próprio conceito de soberania, que estipula que todos os soberanos são iguais e que os Estados soberanos detêm controle absoluto sobre os seus territórios emergiu a partir da Paz de Vestfália de $1648^{16}$.

Após a Primeira Guerra Mundial, com a criação da Liga das Nações, foi instituído o sistema de mandatos para lidar com os territórios que tinham sido anexados pelas potências derrotadas na

\footnotetext{
14 "Il deficit di cristianità e/o di civiltà rendeva la coscienza delle popolazioni non occidentali incapaci di produrre diritto, impediva la loro partecipazione attiva alla vita della comunità Internazionale e le affidava ai principi universali del diritto naturale che gli Stati occidentali avrebbero ritenuto applicabili nei loro confronti."

15 "The naturalist international law which had applied in the sixteenth and seventeenth centuries asserted that a universal international law deriving from human reason applied to all peoples, whether European or non-European. By contrast, positivist international law distinguished between civilized states and noncivilized states and asserted further that international law applied only to the sovereign states which comprised the civilized 'family of nations'."

${ }^{16}$ Ainda, segundo o entendimento de Anghie: "Non-European states lacked this sovereignty, and the development of international law can be seen in part as the 'Expansion of International Society', the process by which Westphalian sovereignty was extended to include the societies of the non-European world.” (ANGHIE, 2006, p. 740)
} 
Guerra - impérios otomano e alemão - e que, consequentemente, não estavam sob a soberania de nenhum Estado. Conforme o sistema de mandatos, previa-se o reconhecimento da promoção do desenvolvimento e bem-estar de colônias e povos de territórios ainda não aptos a serem independentes, sem, entretanto, estabelecer expressamente que as potências teriam conduzido os territórios sob mandato à independência (BIAZI, 2014, p. 161). Ao término da Segunda Guerra Mundial e com a criação da Organização das Nações Unidas, na redação da Carta de São Francisco de 1945, é que se começa a testemunhar uma sensível alteração das relações internacionais.

O direito internacional moderno ainda tem como núcleo essencial as relações interestatais, ou seja, relações que dizem respeito a entidades soberanas e independentes que são consideradas iguais, pelo menos do ponto de vista formal. No capítulo I da Carta das Nações Unidas, na parte referente aos propósitos e princípios da organização, e, especificamente, no primeiro inciso do artigo $2^{\circ}$, afirma-se que: “A organização é baseada no princípio da igualdade de todos os membros.” ${ }^{17}$ No mesmo sentido, o parágrafo $7^{\circ}$ do artigo citado prevê que: “Nenhum dispositivo da presente Carta autorizará as Nações Unidas a intervirem em assuntos que dependam essencialmente da jurisdição de qualquer Estado [...]." ${ }^{\text {18 }}$ Consta, portanto, como um dos princípios basilares da Organização o reconhecimento da soberania e da independência dos Estados membros. Entre os seis órgãos que a Organização ${ }^{19}$ possui, a Assembleia Geral possui a vocação que se pode dizer mais democrática, participativa, uma vez que todos os 193 Estados-membros possuem representante nesse órgão e, ali, possuem direito à igualdade de voto. Não somente os europeus, portanto, mas os Estados do mundo inteiro, em igualdade formal. Conforme o artigo, todo Estado membro possui um voto apenas, apesar das disparidades no que diz respeito a população e recursos econômicos (SHAW, 2008, p. 1211).

Contudo, a realidade de matiz colonialista ainda se fazia presente e, de certo modo, sobreviveu à Carta das Nações Unidas, uma vez que os capítulos XI e XII instituíram os territórios não autônomos ${ }^{20}$ e os territórios sob tutela ${ }^{21}$. Na realidade, o problema da descolonização constituiu uma das preocupações mais relevantes da recém-instituída organização internacional e, nesse contexto, assumiu um papel sem precedentes o princípio de autodeterminação, que sobretudo nos

\footnotetext{
${ }^{17}$ Texto em português da Carta da ONU. Disponível em: <https://goo.gl/NG8bwr>. Acesso em: 20 out. 2015.

${ }^{18}$ Com a exceção das eventuais medidas que a Carta da ONU prevê no capítulo VII.

19 Conselho de Segurança das Nações Unidas (CSNU), Conselho Econômico e Social, Assembleia Geral, Corte Internacional de Justiça, Conselho de Tutela e Secretariado Geral.

${ }^{20}$ Artigo 73 da Carta da ONU. Para os territórios não autônomos, a Carta da ONU previa que se alcançasse gradualmente o autogoverno.

${ }^{21}$ Artigo 75 da Carta da ONU. Para os territórios postos sob tutela era prevista a gradual liberação do controle das potências coloniais, isto é, a independência.
} 
anos 60 e 70 do século XX levou muitas colônias à independência ${ }^{22}$. O movimento político da descolonização, e a doutrina jurídica que a partir dele se formou, foi encarado como uma resposta ao colonialismo, como observa Anghie:

Virtualmente cada aspecto do sistema da ONU participou desse projeto: as disposições da Carta da ONU que lidavam com territórios não autônomos e postos sob tutela, as famosas Resoluções da Assembleia Geral da ONU que articulavam o direito à autodeterminação e as opiniões da Corte Internacional de Justiça (CIJ) referentes ao Saara Ocidental e à Namíbia, todas se ocuparam da questão. A moderna doutrina da autodeterminação, portanto, foi formulada em resposta ao fenômeno global do colonialismo ${ }^{23}$ (ANGHIE, 2004, p. 196, tradução nossa).

Portanto, após a redação da Carta das Nações Unidas, no contexto internacional, sobretudo com o apoio de países socialistas e pelo movimento anticolonialista reunido na Conferência de Bandung de 1955, a validade do sistema colonial, ainda operante por meio do sistema de tutela, começou a ser politicamente questionada, almejando-se, aí, a independência dos países submetidos a domínio estrangeiro. Mesmo que a Carta enunciasse, entre os vários objetivos da Organização, “o princípio da igualdade de direitos e de autodeterminação dos povos”24, as normas, conforme ensina Treves (2005, p. 20-21), tal qual o artigo 73, eram bastante genéricas, por evitar a palavra independência e utilizar a expressão autogoverno. Contudo, no entendimento desse mesmo autor, a Assembleia Geral orientou-se para uma interpretação extensiva da Carta ao declarar que a sujeição dos povos a domínio estrangeiro contrariava as suas disposições (TREVES, 2005, p. 21).

O conceito de Terceiro Mundo como realidade política, um bloco de países que se forma em contraposição aos dois blocos então dominantes, capitalista e socialista, exerceu um papel determinante na subversão histórica internacional do colonialismo. O movimento não alinhado expresso pelos países do Terceiro Mundo, conceito que se consolidou com a Conferência de Bandung $(1955)^{25}$, significou uma "reordenação da política internacional a partir de novas divisões”26. Tratava-

\footnotetext{
${ }^{22}$ Sobre o papel da ONU na descolonização, vide VIRALLY, Michel. Droit international et décolonisation devant les Nations Unies. Annuaire français de droit international, vol. 9, 1963, p. 508-541.

23 "Virtually every facet of the UN system participated in this project: the provisions in the UN Charter that dealt with non-self-governing and trusteeship territories, the famous General Assembly Resolutions articulating the right to selfdetermination and the opinions of the International Court of Justice (ICJ) in Western Sahara and Namibia, all addressed this question. The modern doctrine of self-determination, then, was formulated in response to the whole phenomenon of colonialism."

${ }^{24}$ Art. 1, § 2, da Carta da ONU. Disponível em: <https://goo.gl/NG8bwr>. Acesso em: 17 ago. 2016.

${ }^{25}$ PARK, No-hyoung. The Third World as an International Legal System. Boston College Third World Law Journal, vol. 7, 1987, p. 45.

${ }^{26}$ Conforme constatado por BETTS, o qual afirma que: “The notion of a 'Third World', a reordering of international politics by new divisions, emerged from this conference. This new triangulation was a simple geometry of protest against the East-West division of a capitalist world and a communist world, the one having its magnetic pole in Washington, the other in Moscow, hence the popular term 'bipolarization'. As they moved from colonial status to the condition of nation states, the smaller and middle-size countries desired to avoid overbearing alliances and alignments.” BETTS, Raymond. Decolonization. The making of the contemporary world. London: Routledge, 1998, p. 44.
} 
se de uma rejeição, por parte de países recém-independentes e subdesenvolvidos, à bipolarização política, e consequentemente jurídica, presente na realidade internacional da época. Os Estados africanos, sul-americanos e asiáticos compunham esse bloco, que, apesar da nomenclatura una de Terceiro Mundo, pouco possuía de coerente e homogêneo, senão o fato de se colocarem em posição de rejeição à estrutura dominante. Muito embora tenha o colonialismo se encerrado em termos formais, a presença de novas formas de relações de dominação que se inspiram em traços coloniais pode ser verificada, o que se define como neocolonialismo. Com efeito, esse processo históricopolítico se expressa por meio do direito internacional, também, enquanto instrumento de sua consolidação, segundo Chimni:

O processo de globalização teve efeitos deletérios no bem-estar das populações do Terceiro Mundo. Três bilionários do Norte hoje em dia detêm riquezas que superam o Produto Nacional Bruto de todos os países menos desenvolvidos e seus 600 milhões de pessoas. O direito internacional está exercendo um papel crucial em ajudar a legitimar e sustentar as estruturas e processos desiguais que se manifestam na divisão crescente entre Norte e Sul. De fato, o direito internacional é a principal linguagem em que a dominação está se expressando na era da globalização. Está substituindo os sistemas jurídicos nacionais na sua própria importância e tendo um impacto sem precedentes sobre as vidas das pessoas. Armado com os poderes das instituições financeiras e comerciais a fim de executar uma agenda neoliberal, o direito internacional hoje em dia ameaça reduzir o significado da democracia a eleger representantes que, apesar das afiliações ideológicas, são forçados a perseguir as mesmas políticas econômicas e sociais. Até o discurso internacional sobre os direitos humanos está sendo manipulado para perpetuar e legitimar objetivos neoliberais. Resumidamente, a independência política e econômica está sendo ameaçada por políticas e leis ditadas pelo Primeiro Mundo e pelas instituições que esse controla ${ }^{27}$ (CHIMNI, 2006, p. 3 , tradução nossa).

Novas formas de colonialismo, portanto, encontram-se vigentes no cenário internacional, avançadas por meio de políticas e instrumentos econômicos e culturais desenvolvidos por antigas potências coloniais. Esse fenômeno deságua no que se chama de neocolonialismo. A palavra foi cunhada pelo líder do Ghana - primeira colônia africana a se tornar independente -, Kwame Nkrumah, que, em 1965, escreveu a obra Neocolonialism: The last stage of imperialism, na qual expõe que “[a] essência do neocolonialismo é que o Estado que lhe está sujeito é, na teoria,

\footnotetext{
27 "The process of globalization has had deleterious effect on the welfare of third world peoples. Three billionaires in the North today hold assets more than the combined GNP of all the least developed countries and its 600 million people. International law is playing a crucial role in helping legitimize and sustain the unequal structures and processes that manifest themselves in the growing north-south divide. Indeed, international law is the principal language in which domination is coming to be expressed in the era of globalization. It is displacing national legal systems in their importance and having an unprecedented impact on the lives of ordinary people. Armed with the powers of international financial and trade institutions to enforce a neo-liberal agenda, international law today threatens to reduce the meaning of democracy to electing representatives who, irrespective of their ideological affiliations, are compelled to pursue the same social and economic policies. Even international human rights discourse is being manipulated to further and legitimize neo-liberal goals. In brief, the economic and political Independence of the third world is being undermined by policies and laws dictated by the first world and the international institutions it controls."
} 
independente, e possui todas as armadilhas exteriores da soberania internacional. Na realidade, o seu sistema econômico, assim como sua política, são dirigidas do exterior”28 (NKRUMAH, 1965, IX). Ainda segundo a definição de Young, é possível conceituar neocolonialismo como

[...] uma hegemonia econômica perpétua que significa que o Estado pós-colonial permanece em uma situação de dependência em relação aos donos precedentes, e que os donos precedentes continuam agindo em uma forma colonial para com os Estados precedentemente colonizados $^{29}$. (YOUNG, 2001, p. 45, tradução nossa)

Assim, os países de Primeiro Mundo - já após o final do Segundo Mundo socialista continuariam a intervir nos assuntos internos dos países de Terceiro Mundo, perpetuando, dessa maneira, situações não declaradas, veladas, de dominação e submissão exterior. No ensinamento de Wolkmer, fala-se de uma "herança colonial”:

Os países do Terceiro Mundo carregam uma pesada herança colonial e estão presos a estruturas arcaicas que os subjugam aos centros industrializados e ao capitalismo mundial, representados, depois da Segunda Guerra Mundial, principalmente pelos Estados Unidos (WOLKMER, 2002, p. 35).

A igualdade formal dos Estados soberanos, portanto, tal como afirmada na Carta das Nações Unidas, dificilmente corresponde a uma ordem internacional que, em seu substrato político, reflete situação de igualdade, na qual todas as populações possam ser consideradas emancipadas e detentoras de autodeterminação, não se levando em conta as diferentes condições econômicas, sociais e ambientais em que vivem. Essa proposição se justifica porque, apesar de o colonialismo clássico ter saído de cena - isto é, as antigas colônias formais conseguiram alcançar independência política -, verificam-se, com olhos atentos, novas formas de dominação política que dão azo à utilização do conceito de neocolonialismo. Para responder a essa inquietação, surge, enquanto resposta jurídica discursiva fundada em mudança política pragmática, a contribuição da teoria crítica do direito, considerada como um instrumental apto a refletir possíveis caminhos para a emancipação real dos sujeitos do sistema internacional, o que será abordado na próxima seção.

\footnotetext{
28 "The essence of neocolonialism is that the State which is subject to it is, in theory, independent and has all the outward trappings of international sovereignty. In reality its economic system and its political policy is directed from outside."

29 "[...] a continuing economic hegemony which means that the postcolonial remains in a situation of dependence from its former masters, and that the former masters continue to act in a colonialist manner towards formerly colonized states."
} 


\title{
3 A TEORIA CRÍTICA DO DIREITO ENQUANTO RESPOSTA JURÍDICA
}

O direito pode refletir, em si, dimensão emancipatória, conforme a elaboração da teoria jurídica crítica. Olhando-se por um de seus muitos ângulos, pode-se conceber o fenômeno da teoria crítica do direito, segundo os ensinamentos de Wolkmer, como uma

\begin{abstract}
formulação teórico-prática que se revela sob a forma do exercício reflexivo capaz de questionar e de romper com o que está disciplinarmente ordenado e oficialmente consagrado (no conhecimento, no discurso e no comportamento) em dada formação social e a possibilidade de conceber e operacionalizar outras formas diferenciadas, não repressivas e emancipadoras, de prática jurídica (WOLKMER, 2002, p. 16).
\end{abstract}

Ainda, segundo o autor,

A intenção da teoria crítica é definir um projeto que possibilite a mudança da sociedade em função do novo tipo de homem. Trata-se da emancipação do homem de sua condição de alienado, da sua reconciliação com a natureza não repressora e com o processo histórico por ele moldado (WOLKMER, 2002, p. 9).

Nas palavras de Melo (2011, p. 249), “o que distingue uma teoria crítica das demais posturas teóricas no campo das ciências humanas consiste em seu interesse pelas condições emancipatórias socialmente existentes.” A teoria crítica tenta oferecer um modelo alternativo ao pensamento tradicional, uma vez que esse reproduz, em si, condutas de dominação e opressão. Apresenta, portanto, uma proposta que visa à transformação da sociedade a partir do questionamento dos modelos impostos acriticamente.

Nesse sentido, a construção de uma nova ordem internacional poderia ser imaginada nos termos do instrumental fornecido pela teoria crítica, visando, portanto, à transformação do direito internacional em um direito de emancipação. Essa abordagem crítica permitiria que o direito internacional adquirisse feições capazes de garantir participação plena aos países do Terceiro Mundo (CHIMNI, 2007, p. 500).

Fala-se, assim, de Third World Approach to International Law (TWAIL) como uma proposta de entender a história, a estrutura e o processo do direito internacional pela perspectiva dos Estados do Terceiro Mundo (CHIMNI, 2007, p. 500). Chimni, nesse contexto, aponta para a ameaça concreta de formas de perpetuação do colonialismo, de modo que o direito internacional teria um papel de legitimação delas, constituindo-se como a linguagem principal por meio de que a dominação se expressa na era da globalização (CHIMNI, 2006, p. 3). A abordagem de Terceiro Mundo destina-se a questionar a concepção clássica, oferecendo instrumentos para a articulação política de uma ordem internacional mais solidária, em que todos os Estados possam participar de modo igualitário. É fundamental, para tanto, que os Estados do Terceiro Mundo se desvinculem do controle e da 
dependência em relação aos Estados do Primeiro Mundo em todos os âmbitos - inclusive no âmbito das categorias do conhecimento. Cabe repropor aqui o ensinamento de Quijano, pelo qual

A globalização em curso é, em primeiro lugar, a culminação de um processo que começou com a constituição da América e do capitalismo colonial/moderno e eurocentrado como um novo padrão de poder mundial. Um dos eixos fundamentais desse padrão de poder é a classificação social da população mundial de acordo com a ideia de raça, uma construção mental que expressa a experiência básica da dominação colonial e que desde então permeia as dimensões mais importantes do poder mundial, incluindo sua racionalidade específica, o eurocentrismo. Esse eixo tem, portanto, origem e caráter colonial, mas provou ser mais duradouro e estável que o colonialismo em cuja matriz foi estabelecido. Implica consequentemente, num elemento de colonialidade no padrão de poder hoje hegemônico (QUIJANO, 2005, p. 107).

O direito internacional, posto nessa perspectiva, revela, em seus traços, uma colonialidade do poder, no sentido em que o pensamento europeu colonizador, por meio do conceito de civilização, uma relação de superioridade/inferioridade com os colonizados, e, ainda, ao lado desta, colocam-se outras formas de colonialidade, como a do saber. Conforme Walter Mignolo (2006, p. 11) a lógica da colonialidade opera em três diferentes modalidades: como colonialidade do poder (no domínio político e econômico), como colonialidade do saber (que age em nível epistêmico, filosófico, científico e na relação das línguas com o conhecimento) e como colonialidade do ser (que age no nível da subjetividade, do controle da sexualidade e dos papéis atribuídos aos gêneros). É fundamental para os povos que enfrentam novas formas de colonialismo que disponham de novo instrumental teórico que lhes permita articular a realidade internacional de outra forma. Só por meio dessa atitude de emancipação é possível imaginar uma ordem internacional em que todos os Estados possam participar ativamente, em posição de igualdade e livres de condicionamentos velados. Tudo isso tem início a partir da realidade política, material. O autor indiano Rajagopal fala em incorporação da resistência ao direito internacional, argumentando que

A esperança de que a independência política formal dos territórios colonizados levaria rapidamente à criação de um novo direito internacional se apagou quando os esforços dos novos países independentes para criar uma Nova Ordem Econômica Internacional (NOEI) nos anos setenta se estancaram definitivamente. Durante as últimas décadas tem-se feito cada vez mais difícil depositar as esperanças na capacidade dos Estados do Terceiro Mundo para atuar como os garantes reais das aspirações democráticas das massas na medida em que a soberania dos Estados tem-se fragmentado e repartido para cima (para com as instituições internacionais, como a Organização Mundial do Comércio [OMC] e as instituições de Bretton Woods) e para baixo (para com os atores do mercado e as ONG) ${ }^{30}$ (RAJAGOPAL, 2005, p. 36, tradução nossa).

\footnotetext{
30 "La esperanza de que la independencia política formal de los territorios colonizados llevara rápidamente a la creación de un nuevo derecho internacional se borró cuando los esfuerzos de los nuevos países independientes por crear un Nuevo Orden Económico Internacional (NOEI) en los años setenta se estancaron definitivamente. Durante las dos últimas décadas se ha hecho cada vez más difícil depositar esperanzas en la capacidad de los Estados del Tercer Mundo para actuar como garantes reales de las aspiraciones democráticas de las masas, en la medida en que la soberanía de los
} 
Imaginar uma ordem internacional - e um direito internacional, também - diferente e possível pressupõe que todos os Estados, especialmente os excluídos historicamente, tornem-se protagonistas, e não apenas espectadores, na formação e desenvolvimento do direito internacional, uma vez que, quando chegaram à soberania e à independência, depararam-se com um direito internacional de aplicação universal de cuja formação eles não tinham participado. Espelhando a necessidade de questionar o direito internacional clássico, emergiu a TWAIL, que, conforme Gathii (2011, p. 27), desenvolveu-se nos anos 90 como rede crítica de estudiosos que começou um debate sobre questões de história colonial, poder, identidade e diferença, e, ainda, sobre o que se entende por direito internacional nesse contexto ${ }^{31}$.

Foi aí que os estudiosos filiados à TWAIL começaram a realizar uma releitura da história do direito internacional e dos conceitos criados conforme a tradição jurídica ocidental. Na realidade, como Anghie (2004, p. 202) aponta, esses estudiosos não visavam rejeitar toda a construção feita até então em relação ao direito internacional, mas apenas redimi-lo do passado do colonialismo, expurgando aquelas doutrinas e elementos que criassem e perpetuassem as relações coloniais. Dessa forma, o próprio conceito de soberania era problemático, por ser uma construção ocidental que, quando confrontada com algumas situações, como exploração econômica, dava ensejo a contradições e incoerências. Expurgar os resquícios do colonialismo do novo direito internacional teria demandado, em primeiro lugar, proclamar a soberania permanente sobre os próprios recursos internos, instituindo uma nova ordem econômica internacional. Essa iniciativa possuía certa importância já que os Estados perceberam que a soberania política sem uma correspondente independência econômica teria sido insignificante (ANGHIE, 2006, p. 748).

A independência política era indubitavelmente uma grande conquista, mas não era suficiente para poder-se afirmar que os Estados recém-independentes eram realmente protagonistas da ordem internacional. A dependência dos Estados recém-independentes continuava por meio de outras formas, perpetuando situações de subordinação, de natureza sobretudo econômica, dos países do Terceiro Mundo em relação aos mais desenvolvidos. Até os discursos sobre a proteção internacional dos direitos humanos, por mais que fossem - e continuem sendo - fortemente atrativos em relação aos estudiosos dos países subdesenvolvidos ou em desenvolvimento, representam - para esses

Estados se ha fragmentado y repartido hacia arriba (hacia las instituciones internacionales, como la Organización Mundial del Comercio [OMC] y las instituciones de Bretton Woods) y hacia abajo (hacia los actores del mercado y las ONG).”

${ }^{31}$ Continua o autor: "It has also considered possibilities for egalitarian change in a broad variety of areas in the fields of public international law and international economic law. 2 TWAIL scholarship has addressed multiple issues related to society, politics, identity and economics- with an underlying commitment to democratic values and concerns in relations within and between the Third World and developed countries." 
estudiosos - um motivo a mais para potências intervirem nos assuntos internos de Estados, onde supostamente os mais basilares direitos humanos estariam sendo violados. Isso é o que argumentam alguns autores, como Chimni (2006, p. 16), que afirma que a pretensa inaptidão dos países africanos de governarem a si mesmos é a causa de conflitos internos e violações maciças de direitos humanos, justificando, na visão dos países desenvolvidos, a intervenção e assistência humanitária.

Nesse caminho, portanto, nem mesmo a aquisição da independência política por parte dos países que anteriormente eram colônias era garantia de uma verdadeira autonomia: as relações existentes entre centro e periferia, países desenvolvidos e subdesenvolvidos, continuavam a se reproduzir dentro dos próprios países periféricos. De fato, mesmo aqui elites nacionais mantinham fortes vínculos com os países do centro. Como anteriormente acenado, as próprias instituições financeiras internacionais, como o Banco Mundial e o Fundo Monetário Internacional, exerceram um papel intrusivo nas economias dos países do Terceiro Mundo, fazendo uso de suas prerrogativas para induzir nesses países reformas de estruturas políticas e sociais, em nome da promoção da boa governança (good governance, em inglês) (ANGHIE, 2006, p. 749). Tudo isso, nas palavras de Wolkmer, culminou em muitas contradições:

O sistema de dominação e a estrutura de poder mundial propiciaram uma ordem internacional que apresenta uma racionalidade de contradições, de força, de privilégios e de desigualdades. Impõe-se uma revolução cultural sedimentada na reformulação de princípios e de valores, materializando um novo sujeito histórico e uma nova postura ética na ação dos integrantes do sistema global. (WOLKMER, 1989, p. 31)

Portanto, “a superação da atual ordem internacional começa por uma mudança radical na própria consciência dos atores e por uma alteração no processo de sustentação das formas de tradição e relação existentes” (WOLKMER, 1989, p. 31). Tratar-se-ia de uma prática emancipatória que os povos explorados deveriam empreender a fim de transformar a ordem internacional existente em uma mais equilibrada e democrática. Acredita-se que é nesse sentido que a teoria crítica pode fornecer instrumentos insubstituíveis para que possa de fato averiguar-se essa mudança almejada. E, em particular modo, um segmento da teoria crítica, o dos estudos pós-coloniais, que constitui uma disciplina destinada a estudar os legados do colonialismo ${ }^{32}$. Conforme Leela Gandhi (1998, p. 4), essa disciplina pode ser concebida como “[...] uma resistência teorética à amnésia dos resultados da colonização. É um projeto disciplinar dedicado à tarefa acadêmica de revisitar, lembrar e, sobretudo, examinar o passado colonial.”

\footnotetext{
32 Para aprofundar a questão dos discursos pós-coloniais, vide MELLINO, Miguel. La crítica pos-colonial. Descolonización, capitalismo y cosmopolitismo en los estudios poscoloniales. Buenos Aires: Paidós, 2008.
} 
Trata-se, resumidamente, de discursos críticos que tematizam as questões derivadas das relações coloniais e suas consequências, que frequentemente se alastram até o presente. Tratar-se-ia de fazer uma opção, que Mignolo (2006, p. 16) chama de “giro descolonial”, a saber, pensar a partir de categorias de pensamento negadas. Seria necessário, nesse particular, questionar profundamente os postulados irrefletidos das teorias políticas liberais/neoliberais, sobre cujas contradições o sistema jurídico contemporâneo se funda ${ }^{33}$.

É necessário, para que ocorra uma mudança pacífica na ordem internacional, que se instaure um diálogo entre atores iguais, conscientes das suas próprias capacidades e da sua dignidade igual no plano internacional. Trata-se, no entendimento de Wolkmer, de um projeto de democratização das relações internacionais, em que

[...] o diálogo e a cooperação são indispensáveis na progressiva abolição do velho e comprometido ordenamento jurídico internacional. Trata-se da socialização de um novo Direito, o Direito do diálogo, da participação igualitária, enfim, Direito internacional da autodeterminação e do desenvolvimento (WOLKMER, 1989, p. 37).

Traduzindo de forma adequada a preocupação do presente artigo, mencionam-se as palavras de Anghie (2006, p. 752), que ressaltam a questão de até que ponto e como o direito internacional pode ser usado para promover os interesses dos Estados do Terceiro Mundo, permitindo, por exemplo, que avancem os seus interesses na esfera internacional. É necessário que o direito internacional, para aspirar à verdadeira representatividade dos interesses de todos os Estados, abandone totalmente seus vínculos - declarados e não declarados - com o colonialismo. Acredita-se que a teoria crítica exerça papel fundamental neste giro.

Repisa-se, por fim, que a mudança de mentalidade não é a condição necessária para que ocorra uma subversão das estruturas coloniais de poder, mas o contrário. De fato, é imprescindível uma subversão material dessas estruturas, por meio de lutas histórico-sociais concretas - tal qual o questionamento histórico-político proporcionado pelo surgimento do bloco de resistência do Terceiro Mundo - capazes de provocar uma mudança da ordem internacional atual. Somente o questionamento político e material das estruturas veladas de dominação - sedimentadas não apenas na consciência, mas sobretudo na ordem concreta das sociedades afetadas - pode abrir espaço a um novo discurso teórico internacional.

\footnotetext{
${ }^{33}$ Tese central da seguinte obra de teoria crítica internacional: KOSKENNIEMI, Martti. From Apology to Utopia. The Structure of International Legal Argument. New York: Cambridge University Press, 2005.
} 


\section{CONCLUSÃO}

Existem certas contribuições teóricas ao direito internacional que só podem emergir do bojo das teorias que adotam uma perspectiva crítica e que, de algum modo, buscam contribuir à superação dos efeitos da colonialidade no sistema internacional. A análise realizada por meio deste trabalho buscou revisitar essas contribuições, a fim de resgatar perspectivas alternativas àquela eurocêntrica, dominante no sistema contemporâneo.

Nosso estudo partiu do século XIX, cujos anos testemunharam a consolidação de um direito internacional pautado por uma lógica de inclusão/exclusão, que tinha como fio condutor a pedra de toque europeia denominada civilização. Da contradição fundamental entre barbárie e civilização é que surge a herança teórica do século XX, que, entre inúmeros eventos históricos de caráter sui generis, viu nascer e brotar com mais força o movimento político e jurídico da descolonização e, com ele, o surgimento do bloco dos países de Terceiro Mundo. Como resultado dessa resposta históricopolítica às estruturas dominantes, desenvolveram-se perspectivas teóricas alternativas para lidar com um direito internacional ainda despreparado para enfrentar as novas realidades: uma (terceira) abordagem própria do Terceiro Mundo. Emergiu, aí, um processo de ressignificação de conceitos clássicos do direito internacional, como a própria soberania. Essa abordagem se alinha à perspectiva da teoria crítica, na medida em que traz à discussão o ponto de vista dos sujeitos historicamente excluídos da participação nos processos decisórios internacionais e, nessa extensão, busca jogar luz nas palavras não ditas dos discursos oficiais.

A contribuição do modo crítico de enxergar a realidade internacional aponta para a construção democrática das relações entre os Estados, que tem por pressupostos o estímulo ao diálogo, a cooperação e a participação igualitária de todos os atores envolvidos, com vistas à real autodeterminação e ao desenvolvimento. O pensamento que se engendra a partir do olhar crítico é, por essa razão, o corolário de uma transformação mais profunda do status quo internacional, pois suas categorias teóricas carregam dentro de si um questionamento político de uma determinada configuração de poder presente no sistema jurídico internacional.

Abrir-se às propostas da(s) teoria(s) crítica(s) é, portanto, passo necessário para quem deseja caminhar em direção ao mencionado "giro descolonial”, isto é, uma mudança fundamental, emancipatória, nos próprios termos do pensamento, e não apenas em seu conteúdo. Em suma, esses novos rumos de pensamento operam com base na inclusão dos historicamente excluídos na participação nos processos decisórios internacionais e, portanto, na reformulação do sistema jurídico 
que lhe diz respeito, produzindo-se na comunidade internacional um novo framework de relações e interações entre todos os sujeitos que dela fazem parte.

\section{REFERÊNCIAS}

ANAYA, James. Indigenous Peoples in International Law. Nova Iorque: Oxford University Press, 1996.

ANGHIE, Antony. Francisco de Vitoria and the Colonial Origins of International Law. In: DARIANSMITH, Eve; ANGHIE, Antony (Org.). Imperialism, Sovereignty and Making of International Law. Cambridge: Cambridge University Press, 2004.

ANGHIE, Antony. The Evolution of International Law: colonial and postcolonial realities. Third World Quarterly, vol. 27, n. 5, p. 739-753, 2006.

BETTS, Raymond. Decolonization. The making of the contemporary world. London: Routledge, 1998.

BIAZI, Chiara Antonia Sofia Mafrica. Representações do princípio de nacionalidade na doutrina internacionalista do século XIX na construção do princípio de autodeterminação dos povos: continuidades e rupturas em um discurso liberal. 234 f. Dissertação (Mestrado em Direito) Universidade Federal de Santa Catarina, Florianópolis, 2014.

BLUNTSCHLI, Johann Caspar. Das moderne Völkerrecht der civilisirten Staaten als Rechtsbuch. Nördlingen: Beck, 1878.

BOWDEN, Brett. The Colonial Origins of International Law. European expansion and the classical standard of civilization. Journal of the History of International Law, n. 7, p. 1-23, 2005.

CHIMNI, B. S. The past, present and future of international law: a critical third world approach. Melbourne journal of international law. Vol. 8, n. 2, p. 499-515, 2007.

CHIMNI, B. S. Third World Approaches to International Law: A Manifesto. International Community Law Review, n. 8, p. 3-27, 2006.

COSTA, Pietro. "Direitos Humanos" e “Autodeterminação" dos Povos no Processo de Descolonização. Tradução Arno Dal Ri Júnior. 2011.

DAL RI JR., Arno. A Nação contra o Estado. A Ciência do Direito Internacional no "Risorgimento" italiano. Anuário Brasileiro de Direito Internacional, 1 (2012).

DAL RI JR., Arno. O Direito como historicismo jurídico humanista: Friedrich Carl von Savigny. In: WOLKMER, Antonio Carlos (Org.). Fundamentos do Humanismo Jurídico no Ocidente. São Paulo: Manole, 2005. 
DAL RI JR., Arno. Pasquale Stanislao Mancini. In: DAL RI Jr., Arno; VELOSO, Paulo Potiara de Alcântara; LIMA, Lucas Carlos (Org.). A Formação da Ciência do Direito Internacional. Ijuí: Unijuí, 2014, p. 253-283.

DELOCHE, Maximin. Du Principe des Nationalités. Paris: Guillaumin, 1860.

FAUCHILLE, Paul. Traité de droit international public. Tome 1, Partie 1. Paris: Rousseau et Cie, 1921.

FIORE, Pasquale. Nuovo diritto internazionale pubblico secondo i bisogni della civilità moderna. Milano: Autori-editori, 1865.

FIORE, Pasquale. Trattato di diritto internazionale pubblico secondo i bisogni della civilità moderna. Milano: Autori-editori, 1879.

GANDHI, Leela. Postcolonial theory. A critical introduction. New York: Columbia, 1998.

GATHII, James Thuo. Twail: a brief history of its origins, the decentralized network, and a tentative bibliography. Trade, Law and Development. Vol 3, n. 11, 2011.

HART, Albert B. Selected Adresses and Public Papers of Woodrow Wilson. New York: Boni \& Liveright, Inc., 1918.

HOBSBAWM, Eric. A era do capital - 1848-1875. Tradução Luciano Costa Neto. XV ed. Rio de Janeiro: Paz e Terra., 2009.

HOLTZENDORFF, Franz von. Le principe des nationalités et la littérature italienne du droit des gens. Revue de Droit International et Législation Comparée, 2, 1870.

JOZON, Paul. Exposition à la séance du 17 février 1870 de la Société de législation comparée. Bulletin de la Société de législation comparée, 2 (1870).

KINGSBURY, Benedict. Reconstructing Self-Determination: A Relational Approach. In: AIKIO, Pekka; SCHEININ, Martin. Operationalizing the Right of Indigenous Peoples to Self Determination. Turku: Åbo Akademi, 2000.

KOSKENNIEMI, Marti. The Gentle Civilizer of Nations. The Rise and Fall of International Law 1870-1960. Cambridge: Cambridge University Press, 2001.

KOSKENNIEMI, Martti. From Apology to Utopia. The Structure of International Legal Argument. New York: Cambridge University Press, 2005.

LE FUR, Louis. Precis de droit international public. 1931.

LÊNIN, Vladimir. Obras Escogidas. Tomo 1. Moscú: Progreso, 1961.

MANCINI, Pasquale Stanislao. Della nazionalità come fondamento del diritto delle genti. Torino: tipografia Eredi Botta, 1851. 
MANCINI, Pasquale Stanislao. Direito internacional (Diritto Internazionale. Prelezioni). Ijuí: Unijuí, 2003.

MELLINO, Miguel. La crítica pos-colonial. Descolonización, capitalismo y cosmopolitismo en los estudios poscoloniales. Buenos Aires: Paidós, 2008.

MELO, Rúrion. Teoria crítica e os sentidos da emancipação. Cadernos CRH. V. 24, n. 62, 2011, p. 249-262.

MIGNOLO, Walter; SCHIWY, Freya; MALDONADO-TORRES, Nelson (Org.). (Des)Colonialidad del ser y del saber. Videos indígenas y los limites coloniales de la Izquierda en Bolivia. Buenos Aires: Del Signo, 2006.

NKRUMAH, Kwame. Neocolonialism: The last stage of imperialism. New York: International Publishers, 1965.

NUZZO, Luigi. Origini di una scienza. Diritto Internazionale e colonialismo nel XIX secolo. Frankfurt am Main: Klostermann, 2012.

OPPENHEIM, Lassa. International Law: A treatise. London: Longman Greens and Co., 1905, v. 1.

PADELLETTI, Guido. L'Alsace et la Lorraine, et le droit des gens. Revue de droit international et de législation comparée, III (1871).

PARK, No-hyoung. The Third World as an International Legal System. Boston College Third World Law Journal, vol. 7, 1987.

QUIJANO, Anibal. Colonialidade do poder, eurocentrismo e América Latina. In: LANDER, Eduardo (Org.). A colonialidade do saber: eurocentrismo e ciências sociais. Perspectivas latino americanas. Colección Sur Sur, CLACSO, Ciudad Autónoma de Buenos Aires, Argentina, 2005.

RAJAGOPAL, Balakrishan. El derecho internacional desde abajo: el desarollo, los movimentios sociales y la resistencia del Tercer Mundo. Bogotá: Publicaciones ILSA, 2005.

RIBEIRO, Darcy. O povo brasileiro. A formação e o sentido do Brasil. 2. ed. São Paulo: Companhia das Letras, 1995.

SAVIGNY, Friedrich Carl. System des heutigen römischen Rechts. Erster Band. Berlin: Veit und Comp., 1849.

SAVIGNY, Friedrich Carl. Vom Beruf unsrer Zeit für Gesetzgebung und Rechtswissenschaft. Heidelberg: Mohr und Zimmer, 1814.

SHAW, Malcolm Nathan. International law. Cambridge: Cambridge University Press. 6. ed., 2008.

TREVES, Tullio. Diritto internazionale. Problemi fondamentali. Milano: Giuffrè, 2005. 
VIRALLY, Michel. Droit international et décolonisation devant les Nations Unies. Annuaire français de droit international, vol. 9, 1963.

WOLKMER, Antônio Carlos. Introdução ao pensamento jurídico crítico. São Paulo: Saraiva, 2002.

WOLKMER, Antônio Carlos. O Terceiro Mundo e a nova ordem internacional. São Paulo: Ática, 1989.

WRIGHT, Robin. M. Anthropological Presuppositions of Indigenous Advocacy. Annual Review of Anthropology, vol. 17, 1988.

YOUNG, Robert J. C. Postcolonialism. An historical introduction. London: Blackwell, 2001.

Arno Dal Ri Júnior

Professor de Teoria e História do Direito Internacional na Universidade Federal de Santa Catarina (UFSC). Doutor em Direito Internacional pela Università Luigi Bocconi (Milão), com pós-doutorado pela Université Paris I (Panthéon-Sorbonne). Mestre em Direito e Política da União Europeia pela Università degli studi di Padova. E-mail: arnodalri@gmail.com

Chiara Antonia Sofia Mafrica Biazi Doutoranda em Direito e Relações Internacionais pelo Programa de Pós-Graduação em Direito da Universidade Federal de Santa Catarina (UFSC). Mestre pela mesma instituicão. Membro do Grupo de Pesquisa em Direito Internacional Ius Gentium - UFSC/CNPq. E-mail: merceau@hotmail.it

Taciano Scheidt Zimmermann Mestrando em Direito e Relações Internacionais pelo Programa de Pós-Graduação em Direito da Universidade Federal de Santa Catarina (UFSC) e graduado em Direito pela mesma instituição. Membro do Grupo de Pesquisa em Direito Internacional Ius Gentium UFSC/CNPq. Assessor jurídico no Gabinete do Tribunal de Justiça de Santa Catarina. Email: tacianoz@gmail.com 